\title{
Module of Remote Sensing of the Integrated Federal Information System on Agricultural Lands
}

\author{
Konstantin A. Bulanov', Mikhail A. Burtsev ${ }^{3}$, Pavel V. Denisov ${ }^{2}$, Evgeny A. Loupian ${ }^{3}$, Alexander S. \\ Martyanov $^{2}$, Maria I. Samoletova ${ }^{2}$ Igor I. Sereda ${ }^{2}$, Vladimir A. Tolpin ${ }^{3}$, Ksenia A. Troshko ${ }^{2}$ \\ ${ }^{1}$ Ministry of agriculture of Russia, Moscow, Russia \\ k.bulanov@mcx.ru \\ ${ }^{2}$ Analytical center of the Ministry of Agriculture of Russia, Moscow, Russia \\ p.denisov@mcxac.ru \\ ${ }^{3}$ Space Research Institute, Russian Academy of Sciences, Moscow, Russia \\ evgeny@d902.iki.rssi.ru
}

\begin{abstract}
The Integrated Federal Information System on Agricultural Lands (IFIS AL) of the Ministry of agriculture of Russia was put into operation in April 2018. State monitoring of agricultural lands is one of the missions of this System. The paper describes the main tasks of the System, types and sources of information contained in it. Special attention is paid to the Remote Sensing Module of IFIS AL based on VEGA service of vegetation satellite monitoring. It presents examples of the urgent challenges solving for agriculture by the tools implemented in it. The prospects for the development of the Module are outlined, aimed at improving the mechanism for implementing state monitoring of agricultural lands.
\end{abstract}

Keywords: agriculture, agricultural lands, state monitoring, information system, IFIS AL, remote sensing 


\title{
МОДУЛЬ ДИСТАНЦИОННОГО ЗОНДИРОВАНИЯ ЗЕМЛИ ЕДИНОЙ ФЕДЕРАЛЬНОЙ ИНФОРМАЦИОННОЙ СИСТЕМЫ О ЗЕМЛЯХ СЕЛЬСКОХОЗЯЙСТВЕННОГО НАЗНАЧЕНИЯ
}

\author{
К.А. Буланов ${ }^{1}$, М.А. Буриев ${ }^{3}$, П.В. Денисов ${ }^{2}$, Е.А. Лупян ${ }^{3}$, А.С. Мартьянов ${ }^{2}$, М.И. Самолётова ${ }^{2}$, \\ И.И. Середа ${ }^{2}$, В.А. Толпин ${ }^{3}$, К.А. Трошко ${ }^{2}$ \\ ${ }^{1}$ Министерство сельского хозяйства Российской Федерации, Москва, Россия \\ k.bulanov@mcx.ru \\ ${ }^{2}$ ФББУ «Аналитический центр Минсельхоза России», Москва, Россия \\ p.denisov@mcxac.ru \\ ${ }^{3}$ Институт космических исследований РАН, Москва, Россия \\ evgeny@d902.iki.rssi.ru
}

\begin{abstract}
В апреле 2018 года в Минсельхозе России введена в эксплуатацию Единая федеральная информационная система о землях сельскохозяйственного назначения (ЕФИС ЗСН), предназначенная в том числе для обеспечения государственного мониторинга этих земель. В работе охарактеризованы основные задачи системы, виды и источники содержащейся в ней информации. Особое внимание уделено Модулю дистанционного зондирования Земли (ДЗЗ) ЕФИС ЗСН, разработанного на базе сервиса спутникового мониторинга состояния растительности ВЕГА. Представлены текущие возможности Модуля ДЗ3 и примеры решения актуальных задач государственного мониторинга земель сельскохозяйственного назначения с использованием реализованных в нём инструментов. Обозначены перспективы развития Модуля, нацеленного на совершенствование механизма осуществления государственного мониторинга земель сельскохозяйственного назначения.
\end{abstract}

Ключевые слова: сельское хозяйство, земли сельскохозяйственного назначения, государственный мониторинг, информационная система, ЕФИС ЗСН, дистанционное зондирование

Земли сельскохозяйственного назначения в Российской Федерации занимают второе место по площади после земель лесного фонда - 383,6 млн га, или 22,4\% от площади всего земельного фонда страны [1]. В соответствии с Постановлением Правительства Российской Федерации от 12 июня 2008 г. № 450 за Минсельхозом России закреплена функция осуществления государственного мониторинга земель сельскохозяйственного назначения, включающего мониторинг состояния и использования этих земель. Для обеспечения государственного мониторинга земель сельскохозяйственного назначения, информационной поддержки принятия управленческих решений на основе результатов государственного мониторинга в Минсельхозе России разработана Единая федеральная информационная система о землях 
сельскохозяйственного назначения и землях, используемых или предоставленных для ведения сельского хозяйства в составе земель иных категорий (ЕФИС ЗСН) [2].

ЕФИС ЗСН введена в эксплуатацию приказом Минсельхоза России от 2 апреля 2018 г. №130. Основными задачами Системы являются:

- получение, хранение, обработка сведений об использовании и состоянии земель сельскохозяйственного назначения;

- учет земель сельскохозяйственного назначения (рис. 1);

- систематическое наблюдение за состоянием и использованием земель сельскохозяйственного назначения;

- интеграция и комплексный анализ сведений из различных источников о качественных характеристиках земель сельскохозяйственного назначения и их фактическом использовании;

- визуализация результатов государственного мониторинга земель сельскохозяйственного назначения;

- обеспечение авторизованных пользователей сведениями о землях сельскохозяйственного назначения и аналитической информацией.

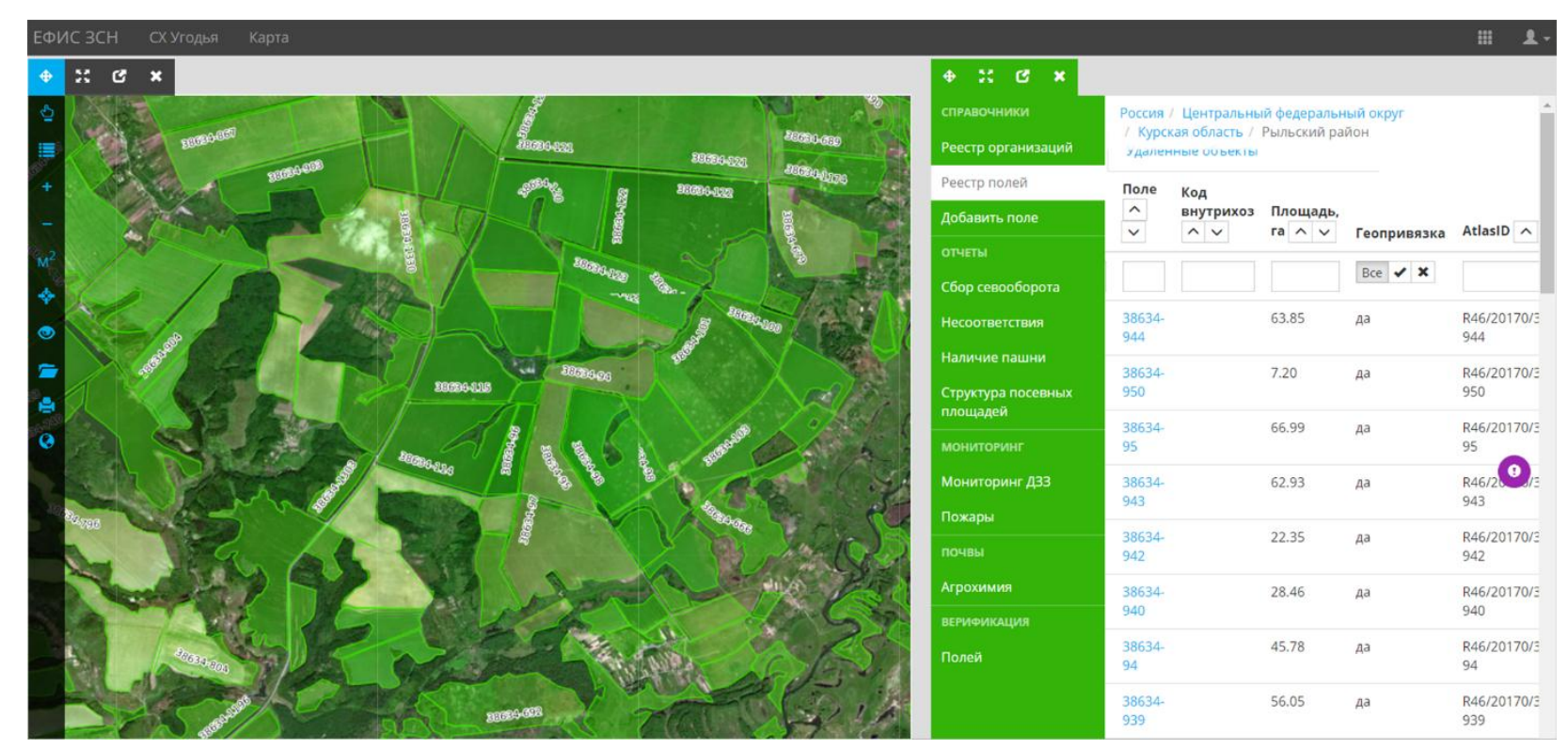

Puc. 1. Пример отображения сельскохозяйственных угодий в ЕФИС ЗСН

Информационное наполнение ЕФИС ЗСН предусматривает сбор данных, состав и возможные источники которых приведены в таблице 1. Основными источниками информации для Системы являются как подведомственные Минсельхозу России учреждения, так и региональные органы управления агропромышленным комплексом (РОУ АПК), опирающиеся, в том числе, на данные региональных информационных систем при их наличии в субъекте. Значительное место при создании ЕФИС ЗСН отведено использованию технологий спутникового мониторинга.

Один из блоков Системы обеспечивает получение информации о состоянии посевов сельскохозяйственных культур с использованием данных спутникового мониторинга. На основе регулярно обновляемых космических снимков MODIS рассчитывается вегетационный индекс NDVI в пределах каждого поля, а также рейтинг (по 5-балльной шкале) полей (рис. 2) и муниципальных образований по состоянию выращиваемых культур на основе этого индекса. 
Таблица 1. ЕФИС ЗСН: виды и источники информации

\begin{tabular}{|c|c|}
\hline Виды информации & Источники информации \\
\hline $\begin{array}{c}\text { Границы и площади сельскохозяйственных } \\
\text { угодий }\end{array}$ & $\begin{array}{c}\text { РОУ АПК, центры и станции агрохимической } \\
\text { службы (АХС), данные дистанционного } \\
\text { зондирования Земли (ДДЗ), Государственный } \\
\text { кадастр недвижимости }{ }^{*} \text { (ГКН) }\end{array}$ \\
\hline Виды сельскохозяйственных угодий & РОУ АПК, АХС, ДДЗ \\
\hline $\begin{array}{c}\text { Выращиваемая сельскохозяйственная } \\
\text { культура и площадь сева }\end{array}$ & 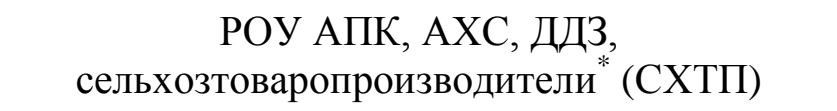 \\
\hline $\begin{array}{c}\text { Состояние посевов сельскохозяйственных } \\
\text { культур }\end{array}$ & ДД3, сХТп* \\
\hline $\begin{array}{l}\text { Сведения о неиспользовании } \\
\text { сельскохозяйственных угодий }\end{array}$ & РОУ АПК, АХС, ДДЗ \\
\hline $\begin{array}{c}\text { Сведения о правообладателях земельных } \\
\text { участков }\end{array}$ & РОУ АПК, ГКН \\
\hline Показатели почвенного плодородия & $\mathrm{AXC}$ \\
\hline $\begin{array}{c}\text { Информация о негативных процессах на } \\
\text { землях сельскохозяйственного назначения }\end{array}$ & АХC, ДДЗ \\
\hline $\begin{array}{l}\text { Информация о чрезвычайных ситуациях на } \\
\text { землях сельскохозяйственного назначения }\end{array}$ & ДДЗ, РОУ АПК \\
\hline $\begin{array}{c}\text { Сведения об объектах и сооружениях } \\
\text { мелиорации }\end{array}$ & $\begin{array}{c}\text { Управления мелиорации земель и } \\
\text { сельскохозяйственного водоснабжения }\end{array}$ \\
\hline
\end{tabular}

" потенциальные источники информации

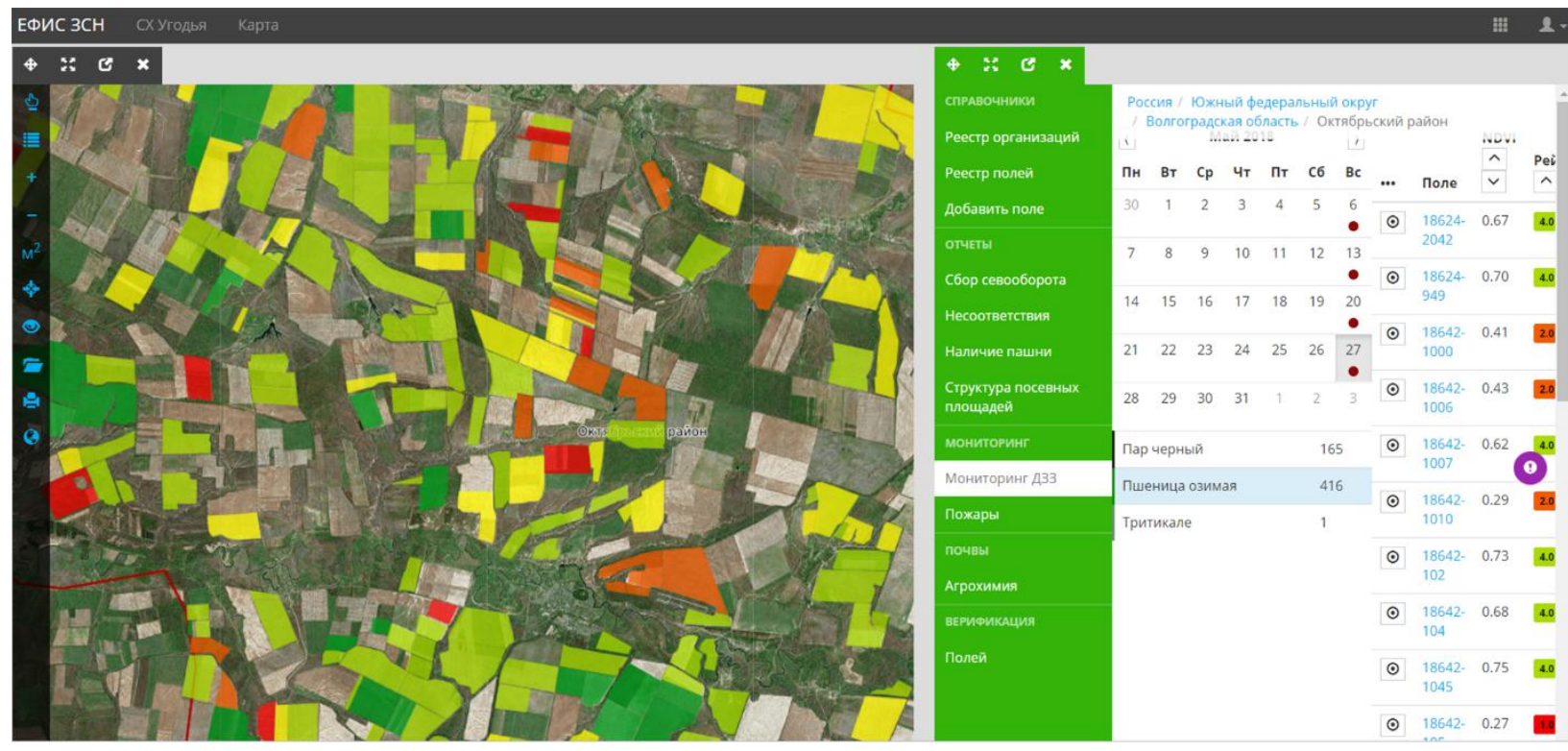

Puc. 2. Пример отображения в ЕФИС ЗСН рейтинга сельскохозяйственных угодий на основе данных спутникового мониторинга 
Для более глубокой работы со спутниковой информацией в рамках системы предусмотрен Модуль дистанционного зондирования Земли (рабочее название - «Аналитик ДЗЗ ЕФИС ЗСН»), основой для которого стал сервис ВЕГА-Science, обеспечивающий возможности распределенной работы со спутниковыми данными, в первую очередь для исследования и мониторинга состояния растительного покрова. Сервис разработан Институтом космических исследований РАН [3]. Он предоставляет широкие функциональные возможности для решения различных задач мониторинга сельскохозяйственных земель и посевов.

Модуль «Аналитик ДЗЗ ЕФИС ЗСН» обеспечивает доступ к:

- космическим снимкам, полученным с российских (Ресурс-П, Канопус-В, Метеор-М) и зарубежных (Sentinel, Landsat, Terra и др.) космических аппаратов в разных спектральных диапазонах и с разным пространственным разрешением (от сверхвысокого до низкого), и информационным продуктам на их основе (вегетационные индексы и др.);

- векторным данным о границах сельскохозяйственных угодий и выращиваемых в их пределах сельскохозяйственных культурах, занесённым в ЕФИС ЗСН;

- картам сельскохозяйственных земель (пахотных земель, посевов озимых и яровых культур и др.), формируемым на основе спутниковых данных;

- метеорологическим данным;

- инструментам обработки и анализа данных.

Космическая съёмка, обеспечивающая большой пространственный охват получаемых снимков при высокой повторяемости наблюдений и достаточном для картографирования сельскохозяйственных земель пространственном разрешении, является одним из наиболее эффективных инструментов для проведения мониторинга земель сельскохозяйственного назначения, особенно в масштабах всей страны. Среди актуальных задач государственного мониторинга земель сельскохозяйственного назначения, которые возможно решать с помощью технологий дистанционного зондирования Земли, можно выделить следующие:

- выделение и/или уточнение границ сельскохозяйственных угодий и посевов сельскохозяйственных культур;

- определение видов сельскохозяйственных угодий;

- распознавание посевов сельскохозяйственных культур;

- оценку состояния посевов сельскохозяйственных культур;

- выявление неиспользуемых сельскохозяйственных угодий;

- выявление негативных процессов на сельскохозяйственных угодьях, включая зарастание древесно-кустарниковой растительностью;

- оценку последствий чрезвычайных ситуаций на землях сельскохозяйственного назначения;

- выявление нецелевого использования земель сельскохозяйственного назначения.

Решение указанных задач по всей территории земель сельскохозяйственного назначения Российской Федерации возможно лишь при наличии надлежащего методического обеспечения и программной реализации соответствующих методик. Так, в 2018 году по заказу Минсельхоза России были проведены разработка и тестирование методик, обеспечивающих решение следующих задач в автоматическом или автоматизированном режиме:

- верификации и коррекции сведений о выращиваемых сельскохозяйственных культурах, предоставленных в ЕФИС ЗСН;

- оценки используемости сельскохозяйственных угодий (рис. 3);

- оценки состояния посевов сельскохозяйственных культур [4];

- формирования информационных бюллетеней о состоянии посевов сельскохозяйственных культур.

Разработка и верификация методик осуществляется с использованием модуля «Аналитик Д33 ЕФИС ЗСН» и системы Вега-Science, которая развивается и поддерживается в рамках Центра коллективного пользования «ИКИ-Мониторинг» [5]. 


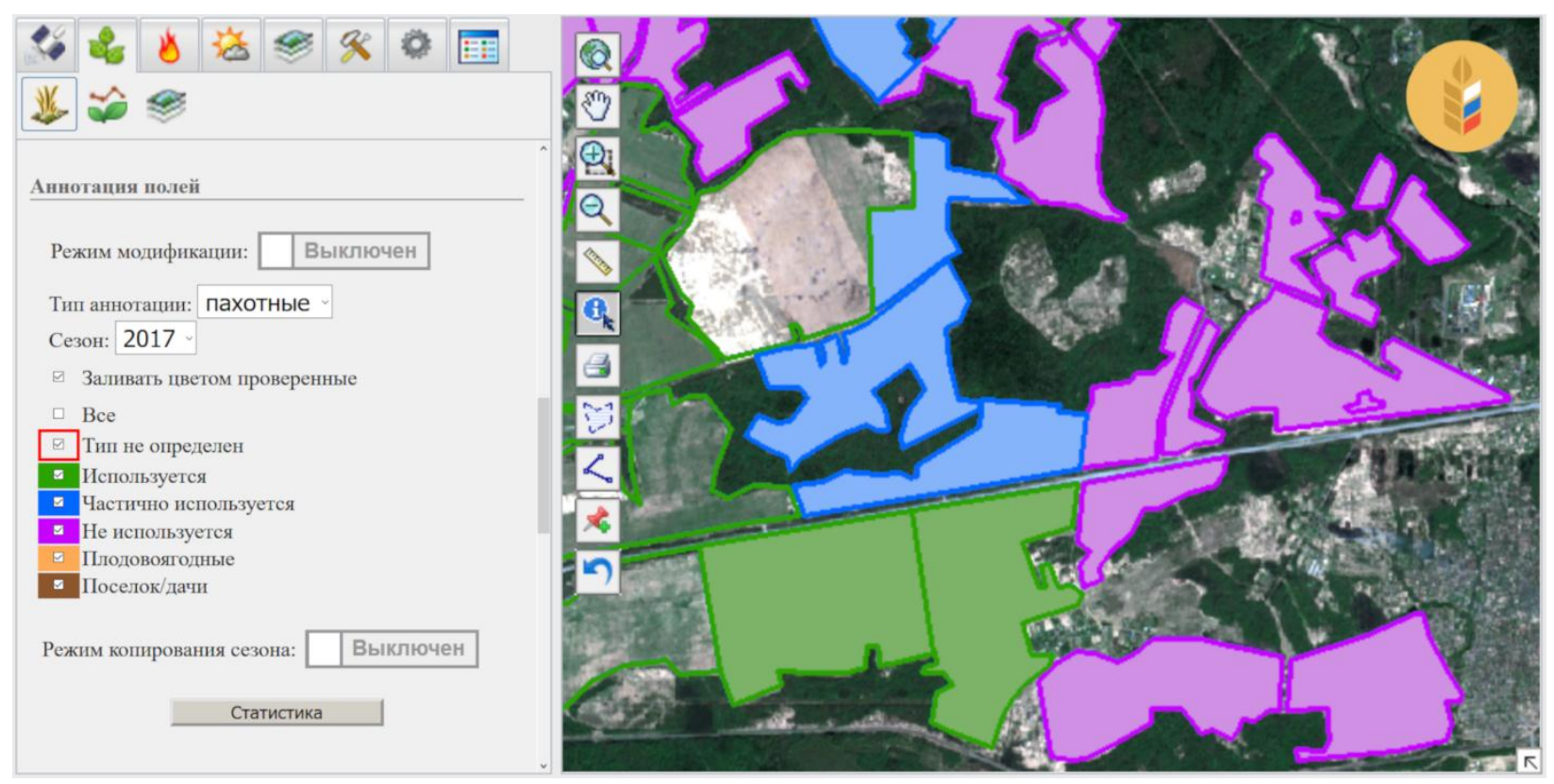

Рuc. 3. Пример оценки используемости сельскохозяйственных угодий в Модуле ДЗЗ ЕФИС ЗСН

Внедрение разработанных методик в Модуль ДЗЗ ЕФИС ЗСН и их дальнейшая эксплуатация позволят повысить эффективность государственного мониторинга земель сельскохозяйственного назначения за счёт использования актуальных и объективных спутниковых данных, охватывающих территорию всех земель сельскохозяйственного назначения Российской Федерации.

\section{References}

[1] Report on the state and use of agricultural lands of the Russian Federation in 2016, 2018, $240 \mathrm{pp}$. (In Russian).

[2] Kozubenko I. S., Beglyarov R. R., Vandysheva N. M., Babak V. A., Denisov P. V., Troshko K. A., The use of remote sensing data in the Integrated Federal Information System on Agricultural Lands (IFIS AL), II Vserossijskaya nauchnaya konferentsiya "Primenenie sredstv distantsionnogo zondirovaniya Zemli v sel'skom khozyajstve”, Saint-Petersburg, FGBNU AFI, 26-28 September 2018. Proc. Conf., 2018, pp. 19-25. (In Russian).

[3] Loupian E.A., Savin I.Yu., Bartalev S.A., Tolpin V.A., Balashov I.V., Plotnikov D.E., Satellite Service for Vegetation Monitoring VEGA, Sovremennye problemy distantsionnogo zondirovaniya Zemli iz kosmosa, 2011, 8(1), pp. 190-198. (In Russian).

[4] Denisov P.V., Krasheninnikova Yu. S., Loupian E.A., Martyanov A.S., Plotnikov D.E., Sereda I.I., Tolpin V.A., Troshko K.A., Observation of winter crops development in Russia in autumn 2018 based on remote sensing data, Sovremennye problemy distantsionnogo zondirovaniya Zemli iz kosmosa, 2018, 15(7), pp. 272-280. DOI: 10.21046/2070-7401-2018-15-7-272-280. (In Russian).

[5] Loupian E.A., Proshin A.A., Burtsev M.A., Balashov I.V., Bartalev S.A., Efremov V.Yu., Kashnitskiy A.V., Mazurov A.A., Matveev A.M., Sudneva O.A., Sychugov I.G., Tolpin V.A., Uvarov I.A., IKI center for collective use of satellite data archiving, processing and analysis systems aimed at solving the problems of environmental study and monitoring, Sovremennye problemy distantsionnogo zondirovaniya Zemli iz kosmosa, 2015, 12(5), pp. 263-284. (In Russian). 